\title{
Lubricating properties of ester oil prepared from bio-based 2, 5-furandicarboxylic acid
}

\author{
Mingjin FAN ${ }^{1, *}$, Jia AI ${ }^{1}$, Shuai ZHANG ${ }^{1}$, Chenlu YANG ${ }^{3}$, Xin DU ${ }^{1}$, Ping $\mathrm{WEN}^{1}$, Xiangyuan $\mathrm{YE}^{1}$, Feng ZHOU ${ }^{2}$, \\ Weiming LIU ${ }^{2}$ \\ ${ }^{1}$ Shanxi Key Laboratory of Phytochemistry, College of Chemistry \& Chemical Engineering, Baoji University of Arts and Sciences, Baoji \\ 721013, China \\ ${ }^{2}$ State Key Laboratory of Solid Lubrication, Lanzhou Institute of Chemical Physics, Chinese Academy of Sciences, Lanzhou 730000, China \\ ${ }^{3}$ College of Chemistry and Molecular Science, Wuhan University, Wuhan 430072, China \\ Received: 05 March 2018 / Revised:25 May 2018 / Accepted: 19 December 2018 \\ (C) The author(s) 2019.
}

\begin{abstract}
The depletion of petroleum resources and the intensification of environmental problems have necessitated the development of renewable products from bio-based chemicals instead of petroleum resources. Herein, a new kind of ester lubricating oil, isooctyl furan dicarboxylate (isooctyl-FD), was prepared from bio-based 2, 5-furandicarboxylic acid. The structure of isooctyl-FD was evaluated using nuclear magnetic resonance imaging and high-resolution mass spectroscopy. Its physicochemical and tribological properties including thermal and oxidation stabilities, flash point and pour point, viscosity and viscosity index, and friction-reducing and anti-wear properties were systematically evaluated. The results show that isooctyl-FD has comparable thermal and oxidation stability to the synthetic ester lubricating oil, isooctyl sebacate (isooctyl-S). Its friction-reducing and anti-wear properties are superior to isooctyl-S; however, its viscosity-temperature and low-temperature properties are inferior to isooctyl-S.
\end{abstract}

Keywords: 2, 5-furandicarboxylic acid; synthetic ester; bio-based platform compound; lubricating oil

\section{Introduction}

There are many types of available lubricants including mineral oil, synthetic oil, and vegetable oil. Among them, mineral oil obtained from petroleum resources is the most commonly used lubricating oil. However, as a non-renewable resource, the total petroleum stock constantly dwindling [1-4]. In particular, the release of a large amount of waste mineral lubricating oil into the environment would result in adverse effects on the ecological environment [5-9]. Considering the relative shortage of petroleum resources and the increase in environmental problems, increasing attention has been focused on the development of renewable biomass-based materials to replace the traditional fossil resources [10-18]. Biomass is inexpensive and ubiquitous. As a sustainable and renewable resource, biomass has great potential to facilitate the transition from non-renewable petroleum resources to renewable bio-energy sources [19-23].

2, 5-furandicarboxylic acid is one of the members of the furan family. This chemical is abundant and readily found in plants and plant straw resources. It can also be obtained from fructose and galactose. Moreover, it contains two carboxyl groups that are considered to be alternatives to p-phthalic acid. Its aromaticity is weaker than that of a benzene ring and it is easily degraded [24-32]. In 2004, 2, 5-furandicarboxylic acid was identified as one of the 12 priority chemicals by the US Department of Energy that would probably be used to build the future "green" chemical industry [33].

* Corresponding author: Mingjin FAN, E-mail: fanmingjin@bjwlxy.edu.cn 
2, 5-furanedicarboxylic acid can be used to synthesize esters because it has two modifiable carboxyl groups. In the present work, 2, 5-furandicarboxylic acid was used to prepare an ester lubricating oil and the product was determined to have good lubrication performance in addition to high thermal and oxidation stability. To the best of our knowledge, there are no published reports on bio-based lubricants to date. The presented procedure is consistent with the requirements of environmental protection and sustainable development. Moreover, it has great significance with respect to the development of green and environment-friendly ester oils.

\section{Experiments}

\subsection{Materials}

2, 5-furandicarboxylic acid (98\%) and p-toluenesulfonic acid (98\%) were purchased from Energy Chemical. Isooctanol (98\%), isooctyl adipate (isooctyl-A, 98\%) and isooctyl sebacate (isooctyl-S, 97\%) were procured from Aladdin Amethyst Chemicals. All the other chemicals were of analytical reagent grade.

\subsection{Synthesis and structural characterization of isooctyl-FD}

The specific preparation reaction equation of isooctyl-FD is shown in Fig. 1. 2, 5-furandicarboxylic acid (100 g, $0.64 \mathrm{~mol})$, isooctanol (500 g, $3.85 \mathrm{~mol})$ and p-toluenesulfonic acid (15 g, $0.07 \mathrm{~mol})$ were mixed and stirred in a round bottom flask in an oil bath at $140{ }^{\circ} \mathrm{C}$ for 6 hours. The reaction mixture was cooled to room temperature (RT) at the end of the reaction. We extracted the crude product using ethyl acetate and subsequently washed it with water three times until it was catalyst-free. The excess isooctanol was removed by vacuum distillation. Finally, pure products were obtained by column chromatography. The molecular structure of the isooctyl-FD was examined using proton nuclear magnetic resonance spectroscopy $\left({ }^{1} \mathrm{H} \mathrm{NMR}, 400 \mathrm{MHz}\right)$ and carbon nuclear magnetic resonance spectroscopy $\left({ }^{13} \mathrm{C} \mathrm{NMR}, 100 \mathrm{MHz}\right)$, performed using an Agilent $400 \mathrm{MHz}$ nuclear magnetic resonance spectrometer (NMR) and high-resolution mass spectra (HRMS) were recorded using a Bruker Dalton micrOTOF-Q II instrument.

\subsection{Physico-chemical properties}

The viscosities of the isooctyl-FD and the reference samples (isooctyl-A and isooctyl-S) were determined based on the ASTM D7042-2012 method. The kinematic viscosities at $40{ }^{\circ} \mathrm{C}$ and $100{ }^{\circ} \mathrm{C}$ were measured with an SVM 3000 Stabinger viscometer and the viscosity index was automatically calculated by the instrument. The densities of the samples were also measured with the viscometer at $20^{\circ} \mathrm{C}$. The viscosities of the samples were tested twice to ensure the accuracy of the data.

The flash points of isooctyl-FD, isooctyl-A, and isooctyl-S were determined using a Stanhope-seta flash point tester (82000-0, U.K.) as per the method of ASTM D3828-09. Flash point refers to the lowest temperature at which a mixture of steam and air that escapes from heating oil flashes instantaneously in contact with a flame. The flash point was tested twice to obtain an average value.

The pour points of isooctyl-FD, isooctyl-A, and isooctyl-S were determined following the ASTM D97-09 method with an accuracy of $3{ }^{\circ} \mathrm{C}$ using a pour point test apparatus manufactured by Lawler Manufacturing (DR4-22 L). The pour points of the samples were measured in $3{ }^{\circ} \mathrm{C}$ decrements until pouring stopped. Duplicate tests were performed and the average value was obtained.

\subsection{Copper strip corrosion test}

The copper strip corrosion tests for isooctyl-FD, isooctyl-A, and isooctyl-S were evaluated using the ASTM D130 method. Polished standard copper strips $($ size $=75 \mathrm{~mm} \times 12.5 \mathrm{~mm} \times 3 \mathrm{~mm})$ were completely immersed in the test samples and maintained at $150{ }^{\circ} \mathrm{C}$ for 3 hours in an oven. At the end of the experiment,

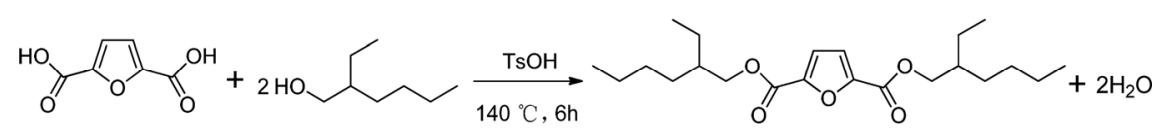

Fig. 1 Reaction equation of isooctyl-FD. 
the copper strips were cleaned with acetone and images were acquired. The color and degree of corrosion of the copper strips were compared with the ASTM copper strip corrosion standard.

\subsection{Oxidation stability}

Rotating bomb oxidation tests of isooctyl-FD, isooctyl-A, and isooctyl-S were performed using a Stanhope-seta rotating bomb oxidation tester (15200-5, U.K.) following the method of ASTM D2272-09. The experiments were performed using a $50 \mathrm{~g}$ sample, copper catalyst, and $5 \mathrm{~mL}$ of distilled water. The vessel was sealed and filled with oxygen at a pressure of $620 \mathrm{KPa}$ and subsequently immersed in an oil bath at $150{ }^{\circ} \mathrm{C}$. The time was recorded when the pressure in the bomb has dropped by $175 \mathrm{KPa}$, and it is used to measure the oxidation stabilities of the samples.

\subsection{Thermal stability}

The thermal stabilities of isooctyl-FD, isooctyl-A, and isooctyl-S were measured using a Netzsch synchronous thermal analyzer system (DSC/DTA-TG, STA 449 F3) under a nitrogen atmosphere with a flow rate of $50 \mathrm{~mL} / \mathrm{min}$. The temperature was set to increase from RT to $600{ }^{\circ} \mathrm{C}$ with a heating rate of $10{ }^{\circ} \mathrm{C} / \mathrm{min}$. As the temperature was increased, the initial and complete decomposition temperatures of the samples were obtained. These values were used to measure the thermal stabilities of the samples.

\subsection{Friction and wear test}

The tribological properties of isooctyl-FD, isooctyl-A, and isooctyl-S for different friction pairs were performed using an Optimol SRV-V (Germany) oscillating reciprocating friction and wear tester at $25^{\circ} \mathrm{C}$. Prior to the tests, all the steel, copper, and aluminum discs were polished in using $400 \mathrm{Cw}, 800 \mathrm{Cw}$, and $1500 \mathrm{Cw}$ $\mathrm{SiC}$ sandpaper and cleaned with ethanol. An AISI 52100 steel ball bearing (diameter $10 \mathrm{~mm}$, hardness $700 \mathrm{HV}-800 \mathrm{HV}$, and mean roughness $20 \mathrm{~nm}$ ) was used for sliding on the surface of a lower disc (AISI 52100 steel: ø $24 \mathrm{~mm} \times 7.9 \mathrm{~mm}$, hardness $850 \mathrm{HV}-870 \mathrm{HV}$; ZQSn 663 copper: ø $24 \mathrm{~mm} \times 7.9 \mathrm{~mm}$, hardness $140 \mathrm{HV}-160 \mathrm{HV}$; 2024 aluminum alloy: ø $24 \mathrm{~mm} \times$ $7.9 \mathrm{~mm}$, hardness $140 \mathrm{HV}-170 \mathrm{HV})$. The sample was dropped on the contact surface and tests were conducted under a load of $100 \mathrm{~N}$, frequency of $25 \mathrm{~Hz}$, amplitude of $1 \mathrm{~mm}$ and duration of $30 \mathrm{~min}$. After the test, the wear volume of the lower test disk was measured using a non-contact surface mapping profiler (BRUKER-NPFLEX). Each sample was tested three times and the average value was reported.

\subsection{Four-ball friction and wear tester}

The tribological properties of isooctyl-FD, isooctyl-A, and isooctyl-S were also tested using a four-ball friction wear tester (MRS-1J) at $25^{\circ} \mathrm{C}$. During the tests, the contact points of the four steel balls (diameter $12.7 \mathrm{~mm}$ ) were immersed in the lubricating oil. The test speed was 1,200 rev/min, the load was $392 \mathrm{~N}$, and the test time was $1 \mathrm{~h}$. Upon completion of the test, the corresponding friction curve and wear spot diameter were obtained.

\section{Results and discussion}

\subsection{Effect of emulsifier concentration}

The chemical structures of isooctyl-FD, isooctyl-A, and isooctyl-S are listed in Table 1 . The structure and purity of isooctyl-FD were confirmed by ${ }^{1} \mathrm{H}$ NMR, ${ }^{13} \mathrm{C}$ NMR and HRMS spectroscopic data and the details of the data are presented below: ${ }^{1} \mathrm{H}$ NMR $(400 \mathrm{MHz}$, $\left.\mathrm{CDCl}_{3}\right) \delta(\mathrm{ppm}), 7.16(\mathrm{~s}, 2 \mathrm{H}), 4.19-4.27(\mathrm{~m}, 4 \mathrm{H})$, 1.66-1.72 (m, $2 \mathrm{H}), 1.27-1.45(\mathrm{~m}, 16 \mathrm{H}), 0.86-0.93$ (m, 12H). $\left.{ }^{13} \mathrm{C} \mathrm{NMR} \mathrm{(100} \mathrm{MHz,} \mathrm{CDCl}_{3}\right) \delta$ (ppm), 158.34, 147.08, 118.18, 68.00, 38.92, 30.49, 29.02, 23.93, 23.04, 14.12, 11.10. HRMS (ESI) calculated for $\mathrm{C}_{22} \mathrm{H}_{36} \mathrm{O}_{5}$ $(\mathrm{M}+\mathrm{Na})^{+}$403.2461, found 403.2471.

Table 1 Chemical structures of isooctyl-A, isooctyl-S, and isooctyl-FD.

Isooctyl-A




\subsection{Kinematic viscosity and viscosity index}

Kinematic viscosity is the measure of the internal friction produced by the molecules when the lubricating oil is subjected to external forces due to relative movement. The moderate viscosity is helpful to form stable oil films between the sliding surfaces, which is favorable to prevent the friction surface wear during the sliding process. The viscosity index indicates the extent to which the viscosity of the lubricant varies with temperature. During the testing, it was determined that the viscosities of isooctyl-FD at $40{ }^{\circ} \mathrm{C}$ and $100{ }^{\circ} \mathrm{C}$ are higher than those of isooctyl-A and isooctyl-S. However, it can be seen from Table 2 that the viscosity index is extremely low. This is related to the molecular structure of the sample. In general, the greater the molecular weight, the higher the viscosity [34-38]. More importantly, the biggest difference between isooctylFD and the reference samples is that it contains an aromatic ring, which leads to a significant decrease in the viscosity index [39].

\subsection{Flash point and pour point}

The flash point is a safety indicator of lubricating oil during storage, transportation, and use. A higher flash point implies that the lubricant is safer. In Table 2, isooctyl-FD has a flash point of $201.5^{\circ} \mathrm{C}$, which is slightly higher the values of isooctyl-A $\left(190.0^{\circ} \mathrm{C}\right)$ and isooctyl-S $\left(194.0^{\circ} \mathrm{C}\right)$. The associated temperature of this parameter is related to the molecular structure. The existence of furan ring can increase the flash point [40].

The pour point is a conventional indicator used to measure the low-temperature flow of lubricants. In general, the pour point of lubricating oil refers to the lowest temperature at which it can flow and when the temperature reaches a certain low level, it solidifies and loses fluidity. The lower this valve, the better the low-temperature fluidity of the lubricant oil is. In Table 2, iooctyl-FD has a pour point of $-13^{\circ} \mathrm{C}$, which is obviously higher than the values for isooctyl-A $\left(<-60{ }^{\circ} \mathrm{C}\right)$ and isooctyl-S $\left(<-60{ }^{\circ} \mathrm{C}\right)$. This is because isooctyl-FD contains an aromatic ring and the introduction of the furan rings increases the pour point of the product $[41,42]$.

\subsection{Oxidation stability}

The oxidation stability refers to the ability of lubricating oil to resist a permanent change of its properties due to the effect of oxygen. As lubricating base oil, ester oils are often operated at high temperatures with strong oxidizing conditions in contact with metal surfaces and oxygen. Therefore, oxidation stability is also an important property of an ester lubricating oil. The oxidation stability of lubricating oil is measured in terms of oxidation life $\left(T_{\mathrm{r}}\right)$. The longer the test time $\left(T_{\mathrm{r}}\right)$, the better its oxidation life. In Table 2, iooctyl-FD has an oxidation life of $45.1 \mathrm{~min}$, which is slightly higher than the value for isooctyl-A (39.0 $\mathrm{min})$ and isooctyl-S (43.9 $\mathrm{min})$. This indicates that isooctyl-FD has better oxidation stability than isooctyl-A and isooctyl-S. According to the studies in Refs. [43-45], the molecular containing shorter ester chains and branches on the ester chains can improve the oxidation stability of a sample. Moreover, the presence of an aromatic ring in the molecule can also improve the oxidative stability of lubricating oil.

\subsection{Copper strip corrosion test}

The copper corrosion test is an important method in the evaluation of the corrosive property of lubricating oil on a metal surface. If a copper strip is kept in lubricating oil for 3 hours at $150{ }^{\circ} \mathrm{C}$, the higher the corrosivity, the deeper the appearance of the color of the copper strip. Images of corroded copper strips and the reference samples are shown in Fig. 2. The copper strip that was corroded by the isooctyl-FD is light yellow, whereas the strips corroded by isooctyl-A and

Table 2 The densities at $20{ }^{\circ} \mathrm{C}\left(d_{20}\right)$, kinematic viscosity at $40{ }^{\circ} \mathrm{C}\left(\mathrm{KV}_{40}\right)$, at $100{ }^{\circ} \mathrm{C}\left(\mathrm{KV}_{100}\right)$, viscosity index (VI), pour point, flash point, and rotating bomb oxidation time $\left(T_{\mathrm{r}}\right)$ of the samples.

\begin{tabular}{|c|c|c|c|c|c|c|c|}
\hline \multirow{2}{*}{ Lubricants } & \multirow{2}{*}{$d_{20}\left(\mathrm{~g} / \mathrm{cm}^{3}\right)$} & \multicolumn{2}{|c|}{$\mathrm{KV}\left(\mathrm{mm}^{2} / \mathrm{s}\right)$} & \multirow{2}{*}{ VI } & \multirow{2}{*}{$\begin{array}{l}\text { Pourpoint } \\
\left({ }^{\circ} \mathrm{C}\right)\end{array}$} & \multirow{2}{*}{$\begin{array}{c}\text { Flashpoint } \\
\left({ }^{\circ} \mathrm{C}\right)\end{array}$} & \multirow{2}{*}{$T_{\mathrm{r}}(\min )$} \\
\hline & & $\mathrm{KV}_{40}$ & $\mathrm{KV}_{100}$ & & & & \\
\hline Isooctyl-A & 0.9317 & 7.6336 & 2.3022 & 122.1 & $<-60$ & 190.0 & 39.0 \\
\hline Isooctyl-S & 0.9142 & 11.4910 & 3.2029 & 153.4 & $<-60$ & 194.0 & 43.9 \\
\hline Isooctyl-FD & 0.9890 & 31.3160 & 4.4807 & 4.50 & -13 & 201.5 & 45.1 \\
\hline
\end{tabular}




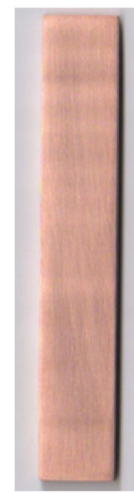

(a)

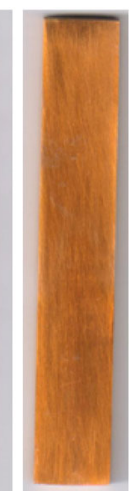

(b)

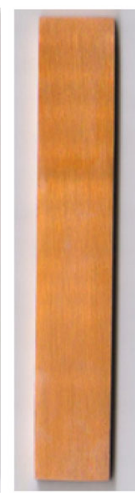

(c)

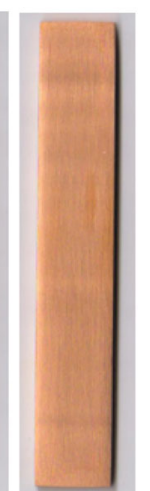

(d)
Fig. 2 Images of (a) new polished copper strip, (b) copper strip immersed in isooctyl-A, (c) copper strip immersed in isooctyl-S, (d) copper strip immersed in isooctyl-FD.

isooctyl-S are darker. A comparison with the ASTM corrosion standard color plate reveals that isooctyl-A and isooctyl-S are more corrosive to copper than isooctyl-FD.

\subsection{Thermogravimetric analysis}

Thermal stability is an index that represents the resistance of a lubricant to cracking and decomposition in a long-term high temperature environment. The thermal stability of an ester lubricating oil depends on its composition, purity, etc. Figure 3 represents the thermogravimetric curves for the thermal decomposition process of isooctyl-FD, isooctyl-A, and isooctyl-S. Based on Fig. 3, it is evident that isooctyl-FD begins to lose weight from $200{ }^{\circ} \mathrm{C}$ and decomposes completely at approximately $300{ }^{\circ} \mathrm{C}$. Its onset decomposition

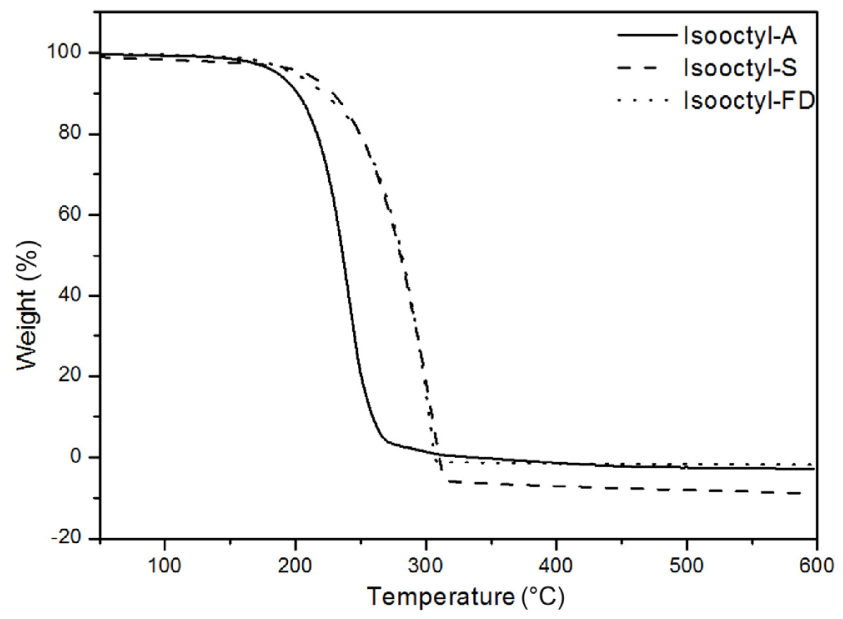

Fig. 3 Thermal decomposition temperatures of isooctyl-FD, isooctyl-A, and isooctyl-S. temperature and total decomposition temperature are approximately the same as that of isooctyl-S. In contrast, the thermal stability of isooctyl-A is relatively poor. The results show that the thermal stability of isooctyl-FD is similar to that of the existed lubricating oil and superior to that of isooctyl-A.

\subsection{Friction and wear test}

The lubricating properties of the samples can be evaluated by measuring their friction coefficients and wear volumes. Friction and wear tests for isooctyl-FD, isooctyl-A, and isooctyl-S were performed on steel/ steel, steel/copper, and steel/aluminum friction pairs at RT. Figure 4 shows the friction coefficients and wear volumes of isooctyl-FD, isooctyl-A, and isooctyl-S on steel/steel friction pairs. From Fig. 4(a), the friction coefficient of isooctyl-FD is much lower than the values of isooctyl-A and isooctyl-S. The shape of the curve is relatively smooth and the running-in time is very short, while the friction coefficients of the reference samples are relatively high with an increasing trend. This indicates that isooctyl-FD can form a stable oil film on the friction surface. It is evident from Fig. 4(b) that the wear volume of isooctyl-FD is also smaller than those of the reference samples. This indicates that isooctyl-FD has better anti-wear properties compared to isooctyl-A and isooctyl-S.

Under the same conditions, isooctyl-FD, isooctyl-A, and isooctyl-S were applied on copper/steel friction pairs. It is evident from Fig. 5(a) that the friction coefficient of isooctyl-FD is much lower than that of isooctyl-A and isooctyl-S. The shape of the friction coefficient curve is very smooth. The running-in time is short and negligible. In contrast, the friction coefficient of isooctyl-A and isooctyl-S is larger, and the curve is unstable. Moreover, as can be seen in Fig. 5(b), the wear volume of isooctyl-FD is also smaller than that of isooctyl-A and isooctyl-S.

Figure 6 shows the friction reducing and anti-wear properties of isooctyl-FD, isooctyl-A, and isooctyl-S on aluminum/steel friction pairs. It is evident from Fig. 6(a) that the friction coefficient of isooctyl-FD is lower than the values for isooctyl-A and isooctyl-S. Overall, the shape of the friction coefficient curves for the three samples on the aluminum friction pair has an increasing trend, but the increase of isooctyl-A 

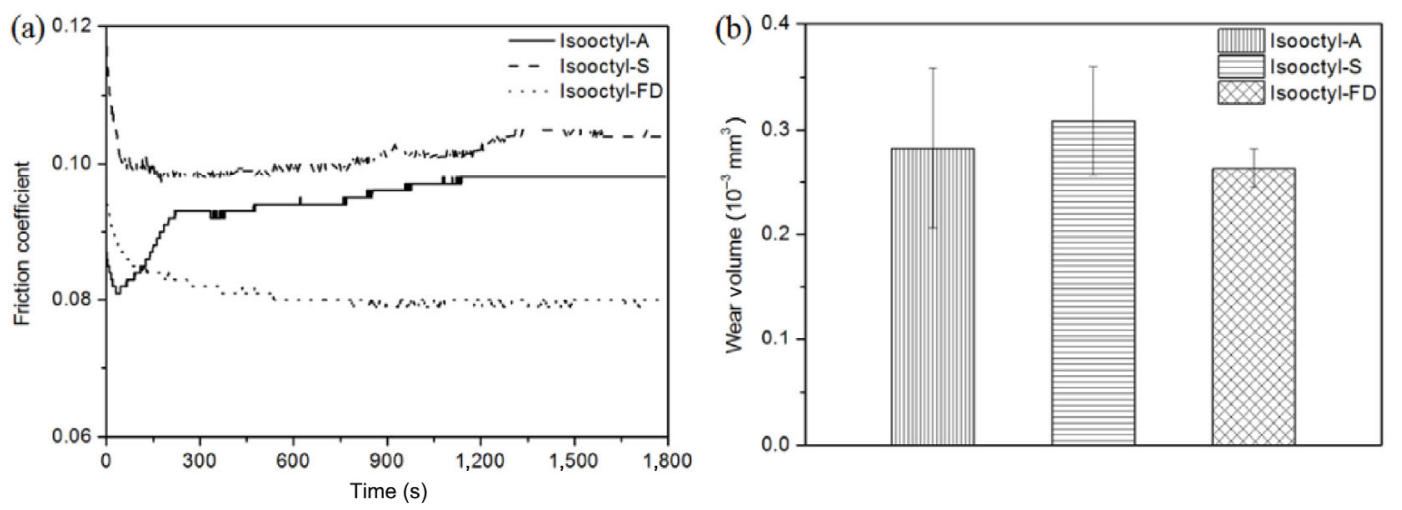

Fig. 4 The evolution of friction coefficients (a) and wear volumes (b) for different samples on steel/steel friction pairs at RT.
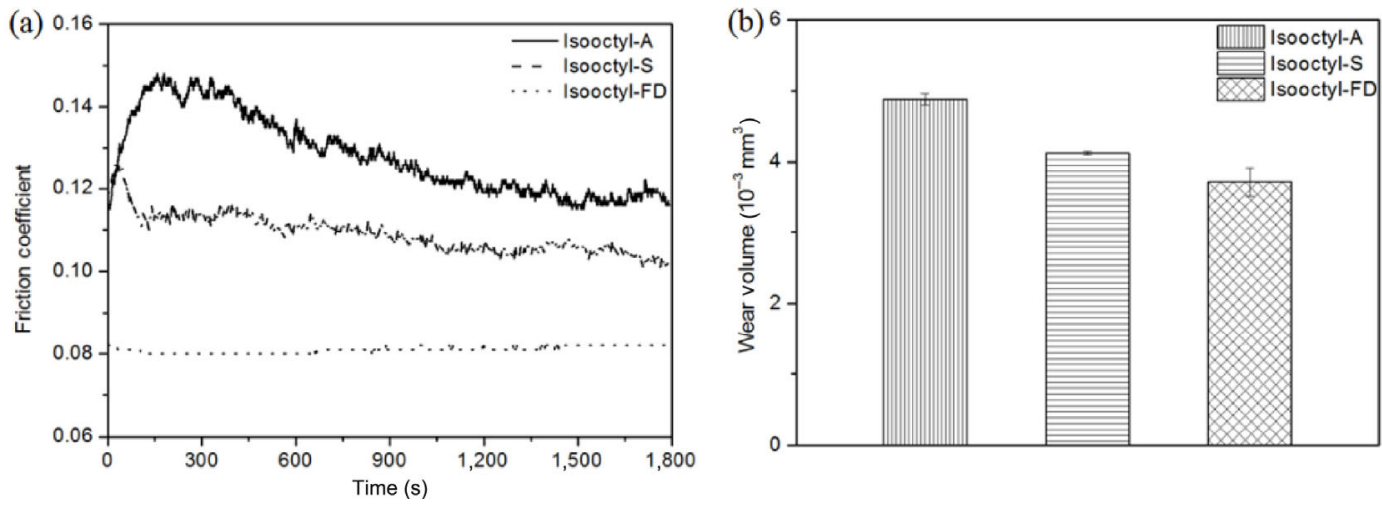

Fig. 5 The evolution of friction coefficients (a) and wear volumes (b) for different samples on copper/steel friction pairs at RT.
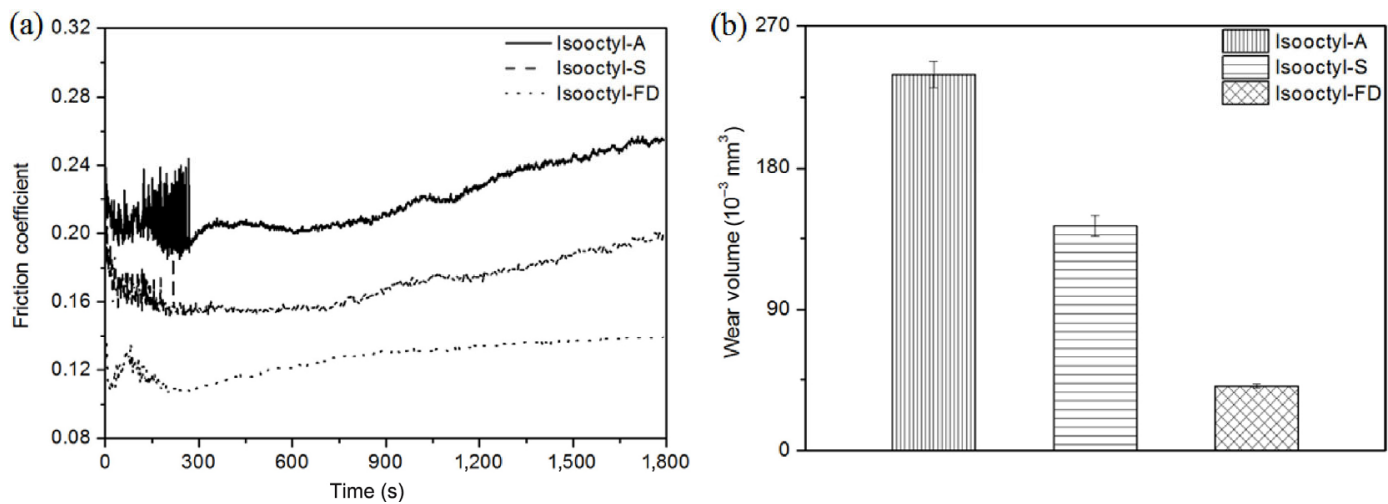

Fig. 6 The evolution of friction coefficients (a) and wear volumes

(b) for different samples on aluminum/steel friction pairs at RT.

and isooctyl-S is more pronounced compared to that of isooctyl-FD. From Fig. 6(b), it can be seen that the wear volume of isooctyl-FD is much less than that of isooctyl-A and isooctyl-S by nearly a quarter of the wear volume of isooctyl-S. These results show that isooctyl-FD has better friction reducing and anti-wear properties compared to isooctyl-A and isooctyl-S on steel/steel, copper/steel, and aluminum/steel friction pairs.

\subsection{Four-ball friction and wear test}

In order to further confirm the good lubricating properties of isooctyl-FD. The tribological properties of the samples were tested using a four-ball friction and wear tester at RT. Figure 7 shows the results of the friction coefficient of the samples. It is evident that the friction coefficient of isooctyl-FD is lower than that of the two reference samples, and a decreasing 


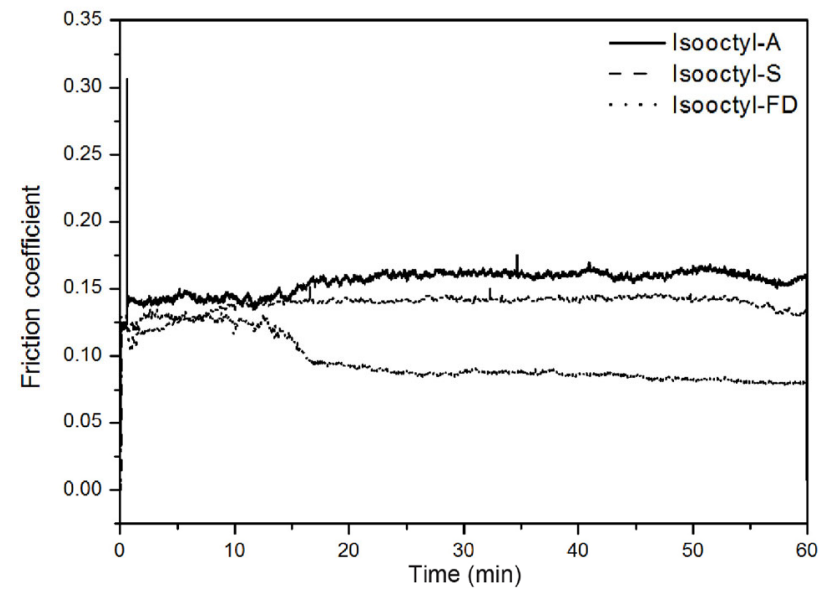

Fig. 7 The evolution of friction coefficients on the four-ball friction and wear tester at RT.

trend is observed in the shape of the curve. The wear spot diameter of isooctyl-A, isooctyl-S, and isooctyl-FD were $1.026 \mathrm{~mm}, 0.850 \mathrm{~mm}$, and $0.810 \mathrm{~mm}$, respectively, indicating that isooctyl-FD has better anti-wear performance than the others. These results are consistent with the results obtained using the SRV-V.

\subsection{Mechanism analysis}

In order to further explain the reduction of friction and the anti-wear mechanism of isooctyl-FD on the different friction pairs, the elemental composition of the worn surface was analyzed using X-ray photoelectron spectroscopy (XPS). It is evident from Fig. 9 that there is no significant difference between the $\mathrm{Cu} 2 \mathrm{p}$ andO1s peaks measured on the worn regions lubricated by isooctyl-FD and the reference samples before and after the application of friction. Therefore, it can be concluded that no reaction films other than that due to oxidation were formed on the sliding surfaces. This implies that there were no obvious tribological reactions other than oxidation on the surfaces. Identification of the source of oxygen is difficult because both the atmosphere and the ester oils are possibilities. However, it can be concluded that physical adsorption films were formed on the metal surfaces due to the polarity of the ester molecules and the aromatic rings contained in isooctyl-FD. The physical adsorption films play a major role, while the chemical reaction (oxidation) films play a minor supporting role in the friction reducing and antiwear efficiency of the ester oils. The former was ultrasonically cleaned prior to XPS testing [46]. XPS testing was also performed on the steel and aluminum metal surfaces (as shown in Figs. 9 and 10), and we arrived at the same conclusions.

\section{Conclusions}

In this experiment, a new synthetic ester lubricating oil, isooctyl-FD, was synthesized by esterification reaction of isooctanol with the bio-based 2, 5furandicarboxylic acid. After a series of physicochemical and tribological property tests, it was determined that isooctyl-FD has comparable thermal and oxidation stability to the synthetic ester lubricating oils isooctyl-A and isooctyl-S. Its friction reducing, and anti-wear properties are better than that obtained for the latter two, but its viscosity-temperature and lowtemperature properties are inferior. The preparation of the lubricating base oil is consistent with the requirements of current environmental protection
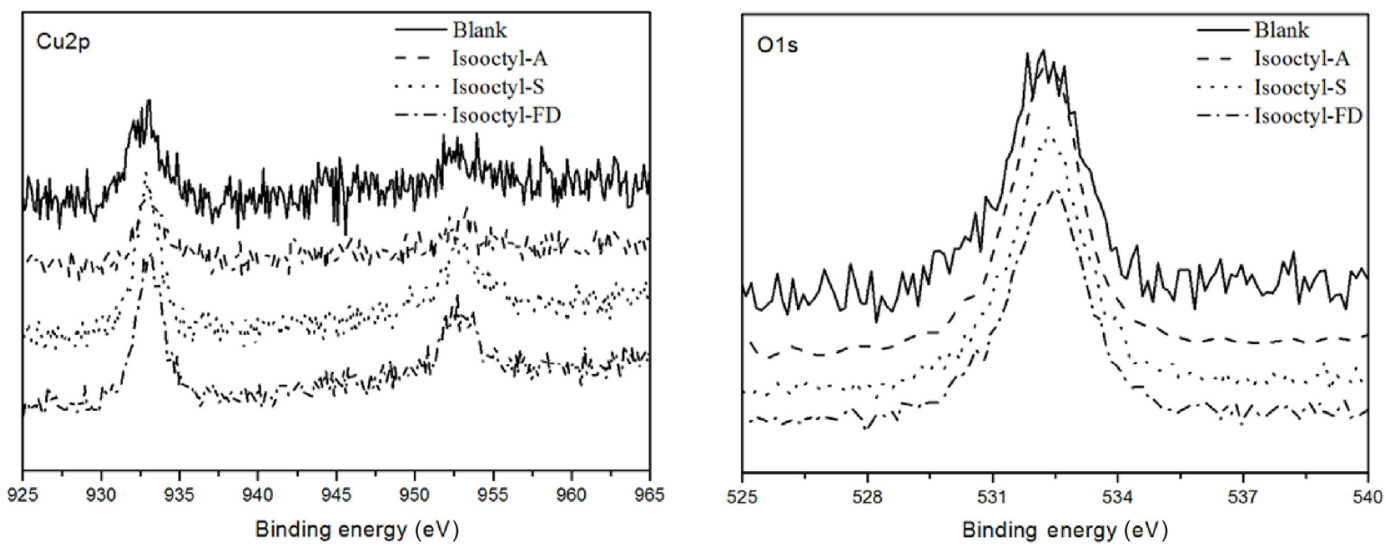

Fig. 8 The XPS spectra of the worn copper surfaces lubricated with different samples at RT. 

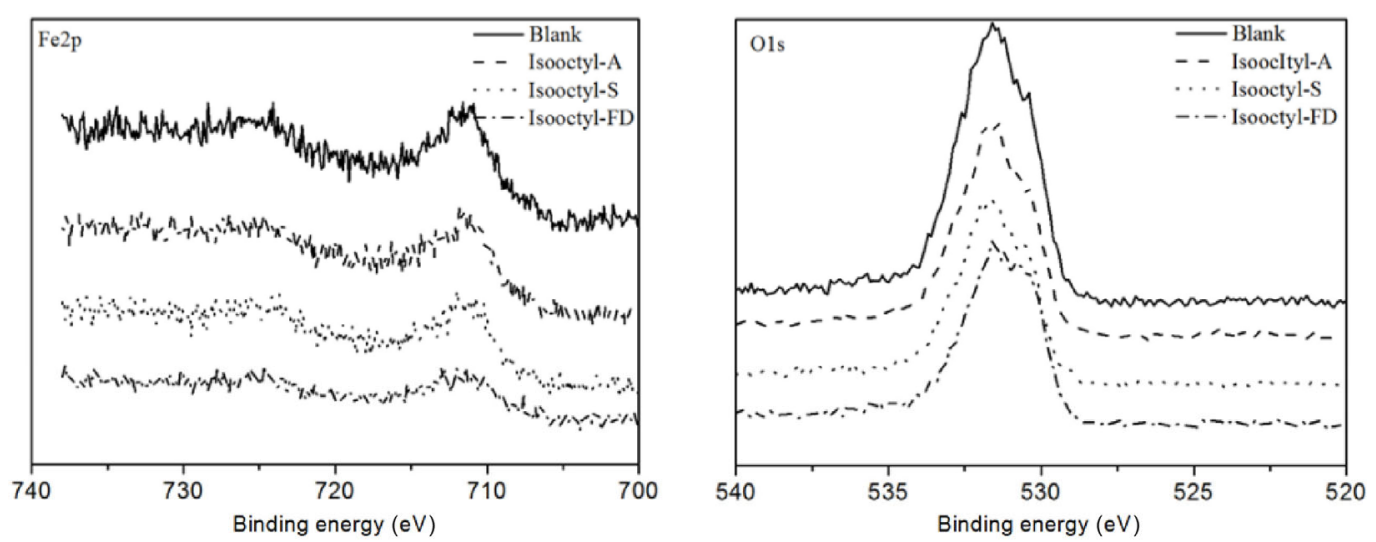

Fig. 9 The XPS spectra of the worn steel surfaces lubricated with different samples at RT.
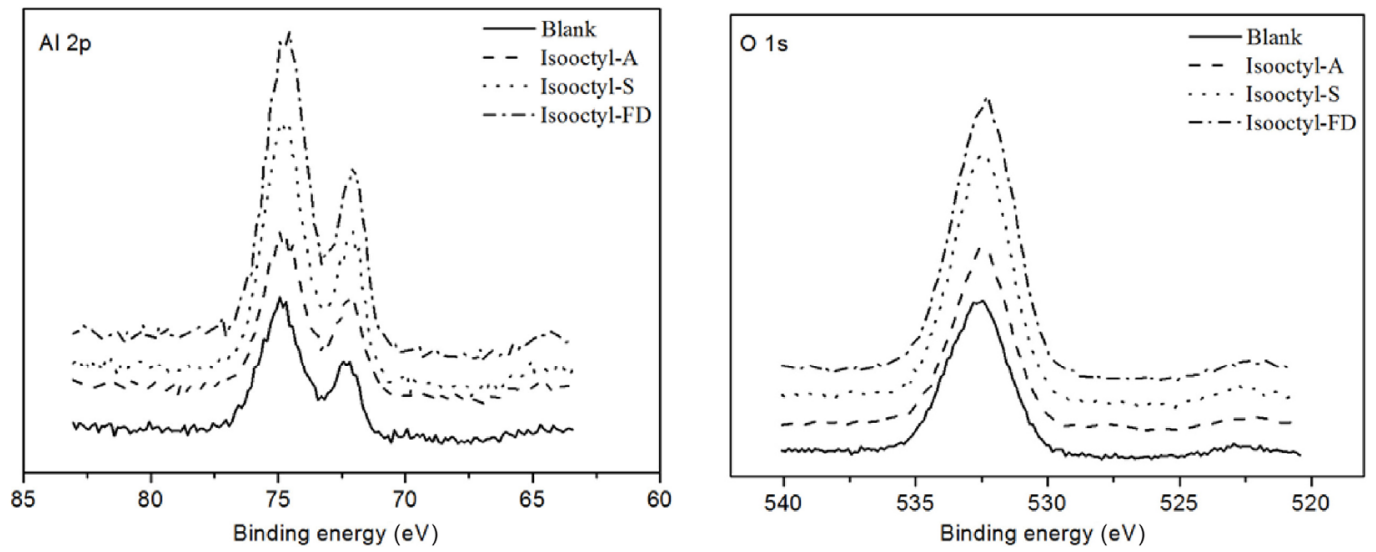

Fig. 10 The XPS spectra of the worn aluminum surfaces lubricated with different samples at RT.

and green sustainable development because the main material used is one of 12 priority chemicals identified by the US Department of Energy for the establishment of a "green" chemical industry.

\section{Acknowledgements}

The work was financially supported by the National Natural Science Fund (51675006), the project of Science and Technology Department of Shaanxi Province (2016JZ017), and the Local Servicing Research Project of the Education Department of Shanxi Province (15JF007).

Open Access: This article is licensed under a Creative Commons Attribution 4.0 International Li-cense, which permits use, sharing, adaptation, distribution and reproduction in any medium or for-mat, as long as you give appropriate credit to the original author(s) and the source, provide a link to the Creative Commons licence, and indicate if changes were made.

The images or other third party material in this article are included in the article's Creative Commons licence, unless indicated otherwise in a credit line to the material. If material is not in-cluded in the article's Creative Commons licence and your intended use is not permitted by statuto-ry regulation or exceeds the permitted use, you will need to obtain permission directly from the copyright holder. To view a copy of this licence, visit http://creativecommons.org/licenses/ by/4.0/.

\section{References}

[1] Adhvaryu A, Liu Z, Erhan S Z. Synthesis of novel alkoxylated triacylglycerols and their lubricant base oil properties. Ind Crops Prod 21(1): 113-119 (2005)

[2] Salih N, Salimon J, Yousif E. Synthetic biolubricant basestocks based on environmentally friendly raw materials. $J$ King Saud Univ - Sci 24(3): 221-226 (2012) 
[3] Shahabuddin M, Masjuki H H, Kalam M A. Experimental investigation into tribological characteristics of bio-lubricant formulated from jatropha oil. Proc Eng 56: 597-606 (2013)

[4] He Y F, Zolper T J, Liu P Z, Zhao Y Z, He X L, Shen X J, Sun H W, Duan Q H, Wang Q. Elastohydrodynamic lubrication properties and friction behaviors of several ester base stocks. Friction 3(3): 243-255 (2015)

[5] Totten G E, Westbrook S R, Shah R J. Fuels and Lubricants Handbook: Technology, Properties, Performance, and Testing. West Conshohocken (USA): ASTM, 2003: 885-909.

[6] Havet L, Blouet J, Valloire F R, Brasseur E, Slomka D. Tribological characteristics of some environmentally friendly lubricants. Wear 248(1-2): 140-146 (2001)

[7] Nagendramma P, Kaul S. Development of ecofriendly/ biodegradable lubricants: An overview. Renewable Sustainable Energy Rev 16(1): 764-774 (2012)

[8] Wang Z, Wang T T, Yang G Y, Gao X L, Dai K. Estimating antiwear properties of esters as potential lubricant-based oils using QSTR models with CoMFA and CoMSIA. Friction 6(3): 289-296 (2018)

[9] Singh Y. Tribological behavior as lubricant additive and physiochemical characterization of Jatropha oil blends. Friction 3(4): 320-332 (2015)

[10] Gallezot P. Cheminform abstract: Conversion of biomass to selected chemical products. Cheminform 43(19): 1538 (2012)

[11] Meyer H P. Sustainability and biotechnology. Org Process Res Dev 15(1): 180-188 (2011)

[12] De S, Malik S, Ghosh A, Saha R, Saha B. A review on natural surfactants. RSC Adv 5(81): 65757-65767 (2015)

[13] Luque R, Lovett J C, Datta B, Clancy J, Campelo J M, Romero A A. Biodiesel as feasible petrol fuel replacement: A multidisciplinary overview. Energy Environ Sci 3(11): 1706-1721 (2010)

[14] Huber G W, Corma A. Synergies between Bio- and oil refineries for the production of fuels from biomass. Angew Chem Int Ed Engl 46(38): 7184-7201 (2010)

[15] Mekonnen T, Mussone P, Khalil H, Bressler D. Progress in bio-based plastics and plasticizing modifications. J Mater Chem A 1(43): 13379-13398 (2013)

[16] Kania D, Yunus R, Omar R, Rashid S A, Jan B M. A review of biolubricants in drilling fluids: Recent research, performance, and applications. J Petrol Sci Eng 135: 177-184 (2015)

[17] Miller S A, Landis A E, Theis T L, Reich R A. A comparative life cycle assessment of petroleum and soybean-based lubricants. Environ Sci Technol 41(11): 4143-4149 (2007)

[18] Anastopoulos G, Kalligeros S, Schinas P, Zannikos F. Effect of dicarboxylic acid esters on the lubricity of aviation kerosene for use in CI engines. Friction 1(3): 271-278 (2013)
[19] Donate P M. Green synthesis from biomass. Chem Biol Technol Agric 1(1): 4 (2014)

[20] Koutinas A A, Du C, Wang R H. Production of chemicals from biomass. In Introduction to Chemicals from Biomass. Clark J, Deswarte F, Eds. Cornwall: John Wiley \& Sons, Ltd., 2008: 246.

[21] Proskurina S, Heinimö J, Schipfer F, Vakkilainen E. Biomass for industrial applications: The role of torrefaction. Renew Energy 111: 265-274 (2017)

[22] Toklu E. Biomass energy potential and utilization in turkey. Renew Energy 107: 235-244 (2017)

[23] Tonini D, Vadenbo C, Astrup T F. Priority of domestic biomass resources for energy: Importance of national environmental targets in a climate perspective. Energy 124: 295-309 (2017)

[24] van Putten R J, van der Waal J C, de Jong E, Rasrendra C B, Heeres H J, de Vries J G. Hydroxymethylfurfural, a versatile platform chemical made from renewable resources. Chem Rev 113(3): 1499-1597 (2013)

[25] Sheldon R A. Green and sustainable manufacture of chemicals from biomass: State of the art. Green Chem 19(3): 950-963 (2014)

[26] Gandini A, Belgacem M N. Furans in polymer chemistry. Prog Polym Sci 22(6): 1203-1379 (1997)

[27] Taarning E, Nielsen I S, Egeblad K, Madsen R, Christensen $\mathrm{C} \mathrm{H}$. Chemicals from renewables: Aerobic oxidation of furfural and hydroxymethylfurfural over gold catalysts. ChemSusChem 1(1-2): 75-78 (2008)

[28] Román-Leshkov Y, Chheda J N, Dumesic J A. Phase modifiers promote efficient production of hydroxymethylfurfural from fructose. Science 312(5782): 1933-1937 (2006)

[29] Zhao H B, Holladay J E, Brown H, Zhang Z C. Metal chlorides in ionic liquid solvents convert sugars to 5-hydroxymethylfurfural. Science 316(5831): 1597-1600 (2007)

[30] Zhang L, Luo X L, Li Y B. A new approach for the aerobic oxidation of 5-hydroxymethylfurfural to 2,5-furandicarboxylic acid without using transition metal catalysts. $J$ Energy Chem 27(1): 243-249 (2018)

[31] Han X W, Li C Q, Guo Y, Liu X H, Zhang Y G, Wang Y Q. $\mathrm{N}$-doped carbon supported Pt catalyst for base-free oxidation of 5-hydroxymethylfurfural to 2,5-furandicarboxylic acid. Appl Catal A Gen 526: 1-8 (2016)

[32] Sousa A F, Coelho J F J, Silvestre A J D. Renewable-based poly((ether)ester)s from 2,5-furandicarboxylic acid. Polymer 98: 129-135 (2016)

[33] Werpy T A, Holladay J E, White J F. Top value added chemicals from biomass volume I-Results of screening for potential candidates from sugars and synthesis gas. Report No.: PNNL-14808, 2004. 
[34] Tsunashima K, Sugiya M. Physical and electrochemical properties of low-viscosity phosphonium ionic liquids as potential electrolytes. Electrochem Commun 9(9): 2353-2358 (2007)

[35] Ghazani S M, Pink D A, Koutchekinia M, Carney J R, Bond R, Rakitsky W, Marangoni A C. Engineering the viscosity and melting behaviour of triacylglycerol biolubricants via interesterification. $R S C A d v$ 5(47): 37180-37187 (2015)

[36] Xu W, Cooper E I, Angell C A. Ionic liquids: Ion mobilities, glass temperatures, and fragilities. J Phys Chem B 107(25): 6170-6178 (2003)

[37] Balakrishnan M, Arab G E, Kunbargi O, Gokhale A A, Grippo A, Toste F D, Bell A T. Production of renewable lubricants via self-condensation of methyl ketones. Green Chem 18(12): 3577-3581 (2016)

[38] Wood-Adams P M. The effect of long chain branches on the shear flow behavior of polyethylene. J Rheol 45(1): 203-210 (2001)

[39] Fan M J, Zhang C Y, Wen P, Yang D S, Zhou F, Liu W M. Relationship between molecular structure and tribological performance of amino acid ionic liquid lubricant. China Surf Eng 30(3): 148-158 (2017)

[40] Erhan S Z, Sharma B K, Liu Z S, Adhvaryu A. Lubricant base stock potential of chemically modified vegetable oils. J Agric Food Chem 56(19): 8919-8925 (2008)

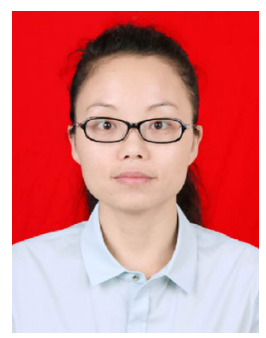

Mingjin FAN. She received her Ph.D. degree in 2007 from State Key Laboratory of Applied Organic Chemistry, Lanzhou University. In 2007, she went to Germany as a post doctor (Alexander von Humboldt Fellowship) and studied in the department of chemistry in Technical University of

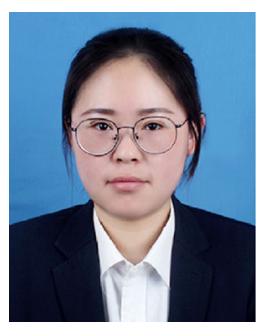

Jia AI. She received her bachelor degree in College of Chemistry \& Chemical Engineering in 2016 from Baoji University of Arts and Sciences,
[41] Kamalakar K, Manoj G N V T S, Prasad R B N, Karuna M S L. Influence of structural modification on lubricant properties of sal fat-based lubricant base stocks. Ind Crops Prod 76: 456-466 (2015)

[42] Kamalakar K, Manoj G N V T S, Prasad R B N, Karuna M S L. Novel acyloxy derivatives of branched mono- and polyol esters of sal fat: Multiviscosity grade lubricant base stocks. J Agric Food Chem 62(49): 11980-11987 (2014)

[43] Zhang Y Y, Zhang F, Thakur K, Ci A T, Wang H, Zhang J G. Effect of natural polyphenol on the oxidative stability of pecan oil. Food Chem Toxicol 119: 489-495 (2018)

[44] Salimon J, Salih N, Yousif E. Improvement of pour point and oxidative stability of synthetic ester basestocks for biolubricant applications. Arabian J Chem 5(2): 193-200 (2012)

[45] Gorla G, Kour S M, Padmaja K V, Karuna M S L, Prasad R B N. Preparation and properties of lubricant base stocks from epoxidized karanja oil and its alkyl esters. Ind Eng Chem Res 52(47): 16598-16605 (2013)

[46] Fan M J, Zhang C Y, Wen P, Sun W J, Dong R, Yang D S, Li W M, Zhou F, Liu W M. High-performance lubricant base stocks from biorenewable gallic acid: Systematic study on their physicochemical and tribological properties. Ind Eng Chem Res 56(34): 9513-9523 (2017)

Munich. On January 2009, she came back and began to work at State Key Laboratory of Solid Lubrication, Lanzhou Institute of Chemical Physics, Chinese Academy of Sciences. From June 2014, she began to work in Baoji University of Arts and Sciences. Her research interests mainly focus on the investigation of new environmentally-friendly lubricants.

Baoji, China. After then, she began to study in the same university as a graduate student. Her research interest is the investigation on novel synthetic lubrication oils. 